\title{
RÁDIO-ESCOLA E MÍDIA-EDUCAÇÃO: UMA PROPOSTA PARA O ENSINO MÉDIO NO CONTEXTO DA CONVERGÊNCIA DE MÍDIAS
}

\author{
SIQUEIRA, Alexandra Bujokas de* \\ MARTINS, Larissa de Almeida**
}

\begin{abstract}
RESUMO
O trabalho relata o processo de desenvolvimento e teste de oficinas de rádio que integraram demandas do programa "Rádio Escola" do Ministério da Educação (MEC) com referenciais internacionais de mídia-educação. O diálogo entre o programa e as demandas se justifica pela necessidade de integrar a escola ao movimento internacional de promoção do engajamento cívico de jovens, empoderando os agentes escolares, por meio da aquisição de habilidades de media literacy. O objetivo foi sugerir aprimoramentos para a política das rádios escolares do Programa Mais Educação do MEC, integrando-as ao contexto mais amplo da educação para a mídia e da cultura digital. A metodologia consistiu-se por um estudo de campo para observar diretamente as atividades propostas a um grupo específico. $\mathrm{O}$ trabalho se fundamenta nos conceitos-chave da mídia-educação e nos multiletramentos. Os dados foram coletados durante a realização das oficinas, utilizando-se de três instrumentos: material produzido pelos participantes, diário de campo e questionário de avaliação, ao final do último encontro. Os dados foram avaliados segundo três categorias: engajamento na proposta, qualidade das produções, percepções dos participantes no que se refere à relevância e viabilidade da proposta. Os resultados permitiram mapear habilidades desenvolvidas com as oficinas e modos de integrar a escola ao contexto mais amplo da cultura digital, usando a linguagem radiofônica.
\end{abstract}

PALAVRAS-CHAVE: Mídia-educação, Multimodalidade, Linguagem radiofônica, Ensino Médio.

\footnotetext{
* Graduada em Comunicação Social (Jornalismo), doutora em Educação com pós-doutorado em Estudos de Mídia na The Open University Inglesa. Professora do Departamento de Filosofia e Ciências Sociais e professora permanente do Programa de Pós-graduação em Educação da Universidade Federal do Triângulo Mineiro. Email: bujokas@uol.com.br
}

** Licenciada em Letras pela Universidade de Uberaba, mestre em Educação pela Universidade Federal do Triângulo Mineiro. E-mail: larissa2m@uberabadigital.com.br 


\section{INTRODUÇÃO}

Mídia-educação e, internacionalmente, media literacy são termos usados para caracterizar uma área interdisciplinar do conhecimento que se preocupa em ensinar aspectos relevantes da inserção dos meios de comunicação na sociedade. O letramento em mídia é então o resultado dessas ações pedagógicas que envolvem, necessariamente, a compreensão crítica e a participação ativa.

Um exame da produção acadêmica brasileira, em particular, indica que as propostas de estudar a mídia não raro se confundem com o uso das mídias na educação, vistas como ferramenta pedagógica para ensinar outros componentes do currículo. Esta última parece ser a perspectiva das rádios escolares que compõem o rol de atividades do Programa Mais Educação (PME) do Ministério da Educação (MEC), foco do estudo aqui apresentado.

Embora o mais sensato seja dizer que a separação entre as duas abordagens tem mais utilidade na investigação acadêmica do que na prática pedagógica, as ênfases em cada uma delas, necessariamente, variam. E o que se vai argumentar aqui é que a ênfase no estudo da mídia em si precisa ganhar atenção e espaço na educação formal, dado o potencial que esta proposta, já bastante amadurecida internacionalmente, tem para formar cidadãos críticos e engajados, atendendo ao pressuposto da nossa Constituição para a qual a educação deve ser promovida "visando ao pleno desenvolvimento da pessoa, seu preparo para o exercício da cidadania e sua qualificação para o trabalho".

Em outras palavras, para que o cidadão comum conheça e saiba reivindicar seus direitos, conscientizar-se sobre a qualidade e a extensão dos seus deveres, exercitar sua identidade, construir opiniões informadas sobre as mais diversas questões de interesse público, é certamente nos meios de comunicação que ele encontra a principal referência. Partindo do pressuposto de que a mídia não é um terreno democrático e pluralista como a publicidade institucional faz parecer, fica evidenciada aqui a relevância da educação para a mídia nas escolas.

É nesse cenário que propusemos uma pesquisa para avaliar e aprimorar a proposta de produção de rádio na escola, no escopo das ações do PME. O objetivo geral foi sugerir aprimoramentos para a política das rádios escolares, integrando-as ao contexto mais amplo da educação para a mídia e da cultura digital. Os objetivos específicos foram: 1. avaliar em que medida as atividades do programa institucional "rádio escola" dialoga com demandas contemporâneas internacionais consideradas no campo da media literacy/mídia-educação; 2. pro- 
por modos de integrar a produção de rádio na escola às abordagens contemporâneas do uso de mídias no contexto da cultura digital; e 3. testar uma oficina de uso da rádio escolar para o Ensino Médio.

A metodologia consistiu-se por um estudo de campo (GIL, 2002; UNESCO, 2013), que tem como procedimento observar diretamente as atividades propostas a um grupo específico, com a intenção de analisar os dados obtidos a partir da avaliação dos resultados da aplicação do piloto.

Inicialmente, foi realizado o estudo sistemático da proposta original da rádio escola no escopo do programa do MEC por meio de análise categorial de conteúdo (BARDIN, 2010) de documentos referentes ao PME disponíveis no site do Ministério da Educação, a fim de isolar os conteúdos que se referem direta ou indiretamente às propostas de atividades vinculadas à rádio escola e à mídia-educação de um modo mais amplo. O conjunto de dados extraídos dos documentos do PME foi confrontado com conceitos-chave da mídia-educação e com a teoria dos multiletramentos.

O referencial construído deu suporte ao desenho de uma proposta de oficinas de rádio considerando o estudo da linguagem e da audiência, de gêneros e formatos próprios do rádio, relações entre técnica, linguagem e representação. As oficinas foram ofertadas a um grupo de professores e estudantes de Ensino Médio de uma escola pública da rede estadual de ensino em Minas Gerais.

Os dados foram coletados durante a realização do teste utilizando-se de três instrumentos: material produzido pelos participantes, diário de campo e questionário de avaliação do curso. Os dados foram então avaliados segundo três categorias: engajamento dos participantes na proposta, qualidade das produções dos participantes, percepção dos participantes no que se refere à relevância e viabilidade da proposta.

Ao término do experimento, foi possível obter um mapeamento preliminar dos recursos necessários para trabalhar com leitura crítica da mídia no escopo das rádios-escola.

\section{CULTURA DIGITAL, CONVERGÊNCIA, LINGUAGENS E EDUCAÇÃO PARA A MÍDIA}


Seja para a informação e a instrução, para o trabalho ou para o lazer, os aparatos digitais, pelo menos em algum momento conectados à internet, plasmam nossas tarefas diárias. Tal expansão das tecnologias digitais no final do século XX e, principalmente, neste início do século XXI caracteriza, segundo Costa (2002, p. 8), a cultura da atualidade "[..] intimamente ligada à ideia de interatividade, de interconexão, de inter-relação entre homens, informações e imagens dos mais variados gêneros".

A esfera que chamamos de cultura digital foi moldada a partir das transformações tecnológicas na comunicação, no entretenimento, na economia, nas formas de trabalho e nos hábitos das pessoas. O problema é que essa nova aparência renova velhas características de desigualdade nas oportunidades de acesso e uso dos recursos propiciados pela cultura digital, e não é difícil localizar os números. Um levantamento divulgado pela Associação Brasileira de Telecomunicações ${ }^{2}$ no início de 2014, por exemplo, mostrou que, entre março de 2013 e março de 2014, foram ativados 49,2 milhões de novos acessos à internet. A banda larga havia crescido 51\% frente ao levantamento anterior e a banda larga móvel cresceu $63 \%$ em relação a março de 2013. Os números impressionam positivamente, mas as características do acesso preocupam.

Estudo realizado pelo IBGE em parceria com o Comitê Gestor da Internet (IBGE/NIC.BR, 2007, p. 38), por exemplo, já em 2005 mapeou o cerne das desigualdades. Considerando a população com 10 anos ou mais de idade, a pesquisa verificou que o Sudeste acessa mais a internet do que as regiões Norte e Nordeste (26\% e $12 \%$ da população, respectivamente), os homens acessam ligeiramente mais do que as mulheres (22\% e $20 \%$ da população, respectivamente), os jovens acessam mais do que os adultos e idosos. Também chamam a atenção os dados relativos aos estudantes: a proporção de pessoas que acessaram a internet no período pesquisado foi de $35,9 \%$. É mais do dobro daquela que não se enquadrava nesta condição: $16,0 \%$. Essa tendência foi identificada tanto na população masculina $(35,6 \%$ e $17,3 \%$, respectivamente) como na feminina $(36,1 \%$ e $14,7 \%$, respectivamente). A escola parece ter um papel importante na inclusão digital.

Desigualdades no acesso e na qualidade do uso são dois aspectos que justificam iniciativas no campo da mídia-educação, já que o estudo da mídia tem como objetivo promover o

\footnotetext{
${ }^{2}$ Números disponíveis na página "Consulta à Base de Dados - Relatórios Séries Temporais Customizados" da Associação Brasileira de Telecomunicações, disponível em www.telebrasil.org.br. Acesso em 18 março 2015.
} 
desenvolvimento de habilidades de acesso, análise e uso de conteúdos e ferramentas (OFCOM, 2004; UNESCO, 2013).

Mesmo que não seja o objetivo principal das mídias, elas acabam tomando parte do processo de educação já que “[...] fornecem a nós a maior parte de nossas informações sobre o processo político; e nos oferecem ideias, imagens e representações (tanto factuais e ficcionais) que, inevitavelmente, moldam a nossa visão da realidade" (BUCKINGHAM, 2003, p. 5, tradução nossa). Consequentemente, a qualidade das oportunidades de acesso e uso da cultura digital que temos, no longo prazo, molda a qualidade de nossa capacidade conhecer, refletir, formar opiniões e construir nossas próprias identidades individuais e de grupo. A escola, como espaço hegemônico de educação, não pode se furtar à responsabilidade de ensinar a lidar com as mídias e sua cultura de maneira crítica e criativa. Resta saber como fazer isso.

Em sentido muito elementar, a educação para a mídia promove uma espécie de letramento multimodal. Conforme Burn e Durran (2007, p. 2, tradução nossa), esse letramento é, necessariamente, transformativo e criativo:

Ele [o letramento midiático] envolve não só a compreensão do texto mas também, em diferentes graus, envolve refazer aquele texto. Esse processo sempre envolve operações mentais para as quais professores, psicólogos, acadêmicos e especialistas em letramento não têm acesso direto. $\mathrm{O}$ trabalho dessas pessoas começa no momento em que o trabalho transformativo [dos aprendizes] se torna externo, mais imediatamente com o discurso, mas também através da escrita, da dramatização, do design visual e assim por diante.

O amalgamento de linguagens, a recriação de mensagens e a troca de papéis entre emissor e receptor são algumas das características identificadas por Jenkins (2008) no fenômeno que ele chama de "cultura da convergência". Para além do uso de aparatos digitais conectados à internet, o autor vê uma transformação nos modos de relacionamento com as mídias. $\mathrm{O}$ argumento é que vivemos numa época caracterizada por velhas e novas mídias colidindo, mídias corporativas e alternativas se cruzando, o poder do produtor e do consumidor interagindo de formas imprevisíveis. A convergência, portanto, não é só tecnológica, mas cultural; e a participação, como se sabe, não é igualitária como o discurso das corporações tenta fazer parecer. Participar dessa nova paisagem midiática requer aprender a navegar por modos de representação diferentes e, não raro, conflitantes, fazendo escolhas conscientes sobre as formas mais adequadas de expressar ideias em cada contexto. 
Reafirma-se aqui o argumento de que se trata de uma cultura, da qual alunos e alunas que estão na escola, de algum modo, estão participando (como sugerem, inclusive, os números do IBGE comentados anteriormente), embora ainda se saiba muito pouco sobre a qualidade dessa participação.

O cenário se torna ainda mais nebuloso quando o estudo da mídia envolve o trato de gêneros e linguagens pouco familiares para a prática pedagógica: fotografia, histórias em quadrinhos, cinema, videoclipe de publicidade, mashups, programação etc. Apesar da aparente diversidade, todos esses textos têm uma característica em comum: podem ser reduzidos à categoria de "multimodais", isto é, textos que usam mais de um modo semiótico ou canal de comunicação (KRESS, 2000). Estudar criticamente a mídia na perspectiva da multimodalidade envolve olhar cada um dos componentes da mensagem, a fim de tentar compreender o modo como cada um deles comunica significados em separado e combinados, uma vez que é da combinação que emergem as conotações.

No contexto da cultura da convergência, não é exagero argumentar que a linguagem escrita foi deslocada da centralidade nos processos de comunicação. Com a crescente importância da informação visual nas multitelas do cotidiano, a forma de ler também está sofrendo transformações - e requer conceitos estruturantes e práticas de ensino e aprendizagem mais apropriados.

Segundo Cope e Kalantzis (2000, p. 2, tradução nossa), “[...] em uma pedagogia de multiletramentos, todas as formas de representação, incluindo a língua, são consideradas como processos dinâmicos de transformação em vez de processos de reprodução". Dessa forma, os indivíduos multiletrados devem ser capazes de produzir as suas representações e de construírem significados a partir de remakes de outros suportes midiáticos. Os produtores de significados são vistos como designers.

Para Buckingham (2003, p. 38, tradução nossa) o letramento midiático "não é apenas uma espécie de kit de ferramentas cognitivo que permite às pessoas entender e usar a mídia”, mas "uma forma de alfabetização crítica, que envolve análise, avaliação e reflexão. Implica na aquisição de metalinguagem, isto é, um meio de descrever as formas e estruturas de diferentes modos de comunicação".

Enfim, ler criticamente, apropriar-se, recriar, remixar são habilidades que podem ser desenvolvidas em práticas pedagógicas de mídia-educação. No cenário internacional (OFCOM, 2004; UNESCO, 2013; AML, 2015; LUSTED, 1991; QCA, 2003; KELLNER E 
SHARE, 2008), há certo consenso em torno dos chamados "conceitos-chave", tidos como guias para orientar o estudo da mídia. Pelo menos quatro deles são comuns às diversas iniciativas: linguagem, audiências, instituições de mídia e representação.

\section{CONCEITOS-CHAVE DA MÍDIA-EDUCAÇÃO}

Estudar a mídia a partir dos conceitos-chave traz algumas vantagens pedagógicas. É possível fazer uma abordagem abrangente e diversificada da cultura midiática, já que não se foca um texto ou linguagem específicos. As atividades podem incluir todas as etapas do ciclo de comunicação, desde as motivações do emissor, os processos de codificação e decodificação até as respostas da audiência. Ao desmontar, analisar comparativamente, remontar e construir textos midiáticos, as atividades fazem com que o aprendiz se distancie do texto, analise e sintetize dados e pontos de vista, fomentando atitudes críticas.

Para Buckingham (2003), a capacidade de argumentação baseada nas evidências do texto deve ser mais valorizada do que a meta de chegar a uma resposta certa previamente definida. Não há, portanto, um cânone de como fazer e do que ensinar, mas sim orientações de como pode ser feita a educação para a mídia e sob quais formas e aspectos podemos analisar e produzir conteúdo.

A Figura 1, a seguir, organiza os quatro conceitos, a partir das habilidades centrais de leitura crítica da mídia. A descrição detalhada virá a seguir.

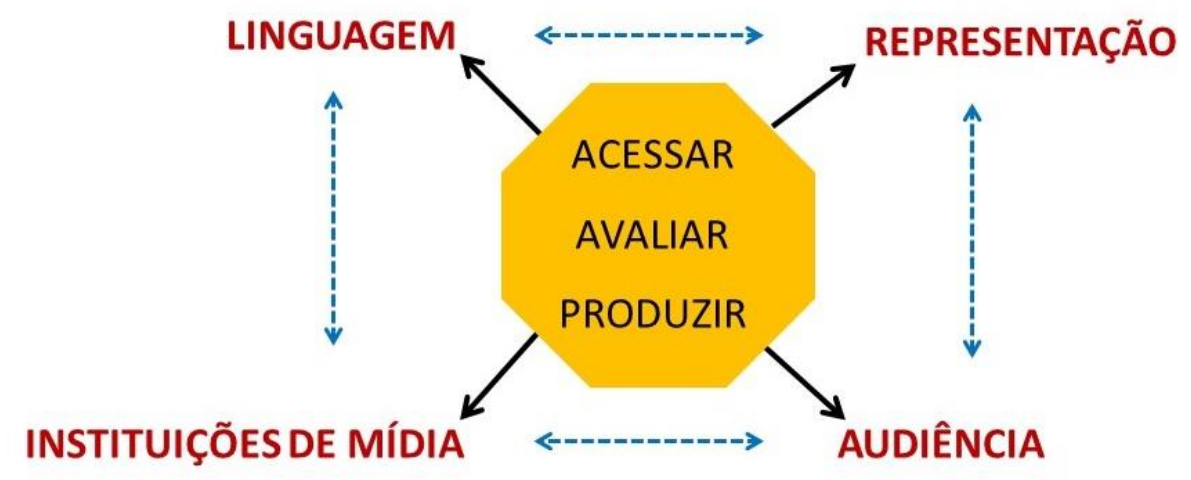

Figura 1: Conceitos-chave da Mídia-educação Fonte: Elaborado pelas autoras 


\subsection{Representação}

O conceito-chave da representação parte do princípio de que a realidade não é apresentada fatidicamente, mas reconstruída por meio de técnicas de produção e recursos de linguagem, e nos convida a ver o mundo por alguns caminhos específicos, desprezando outros. Assim, representações midiáticas são "obrigadas a serem tendenciosas". O trabalho essencial da mídia-educação, a partir desse conceito-chave, é investigar pontos de vista e valores por detrás dos textos midiáticos, tecendo hipóteses sobre como e porquê alguns grupos são representados, quais estereótipos estão impregnados, se são reais do ponto de vista de seus contextos.

\section{2 Linguagem}

O uso de códigos e convenções já estabelecidos no imaginário das pessoas pode invocar emoções particulares. Analisar todos esses usos, em leitura crítica de mídia, é "[... investigar em que medida as características da linguagem produzem sentido e que este não é algo óbvio e transparente em relação à realidade, mas resultado do emprego de uma série de procedimentos técnicos e simbólicos que reconstroem a realidade na tessitura da mensagem" (SIQUEIRA, 2013, p. 13). Particularmente desafiante é investigar os aspectos da linguagem que já se tornaram naturalizados e amplamente aceitos (BUCKINGHAM, 2003), como por exemplo, o uso de falas estereotipadas para as orientações de gênero, ou uma música com melodia cativante, porém com letra que reforça preconceitos. Tais situações muitas vezes passam despercebidas pelo público e cabe ao educador para a mídia aprimorar o olhar sobre esses aspectos.

\subsection{Audiência}

Estudar a audiência implica em aprender "[...] a identificar como os códigos e as convenções de linguagem são usados para criar tipos específicos de representações que terão apelo a certos públicos" (UNESCO, 2013, p. 101), e como esses públicos respondem à mensagem. Como lembra Buckhingam (2003, p. 59, tradução nossa), estudar a audiência significa 
observar de que maneira o "[...] público se torna alvo e como medir o interesse e a atenção, é tentar entender como a mídia circula e é distribuída e observar as diferentes maneiras pelas quais os indivíduos e os grupos sociais usam, interpretam, tentam entender e refletir sobre seus próprios usos das mídias”.

\subsection{Instituições de mídia}

Este conceito se preocupa com as rotinas institucionalizadas de produção e seu reflexo no modo como os diversos assuntos são representados. Conforme Willians (1985, p. 152, tradução nossa), instituição “[...] é um nome dado para uma ação ou um processo que se repete e que, em certo estágio, torna-se um conceito geral e abstrato, passando a descrever alguma coisa aparentemente objetiva e sistemática". É neste estágio que as instituições se tornam ideológicas, e cabe à leitura crítica tentar reconstruir o percurso histórico, do processo inicial à abstração.

Dessa forma, estudar o ciclo de produção e distribuição de mensagens a partir do conceito de instituições de mídia é conhecer as práticas profissionais, reconhecer como as corporações compram e vendem mídia e como o lucro é obtido; investigar quem controla a produção e a distribuição de conteúdo em escala global, que tipo de liberdade de expressão e de opinião é garantida legalmente; como é o acesso e a participação da população nas mídias; é se perguntar: “quais vozes são ouvidas na mídia? Quem são os excluídos, e por quê?” (BUCKINGHAM, 2003, p. 54, tradução nossa).

Portanto, ao se propor um estudo de mídia na escola é conveniente manter o olhar sistêmico, que contemple os quatro conceitos-chave durante as etapas de realização. Dessa forma, integra-se aprendizagem técnica, exercício da liberdade de expressão, desenvolvimento de habilidades de leitura e escrita, mas também reflexão social e auto-reflexão. Afinal, “[...] um dos objetivos da mídia-educação é encorajar estudantes a refletirem sobre as escolhas que devem tomar, e considerar suas consequências" (BUCKINGHAM, 2003, p. 57, tradução nossa).

\section{RÁDIO-ESCOLA: O ORIGINAL E O REVISITADO}


O financiamento de rádios escolares para escolas públicas de educação básica é uma das iniciativas contempladas pelo Programa Mais Educação do MEC. Esse programa foi instituído pela Portaria Interministerial n ${ }^{\circ}$ 17/2007 (BRASIL, 2007) e pelo Decreto $n^{\circ} 7.083$, de 27 de janeiro de 2010 (BRASIL, 2010), e integra as ações do Plano de Desenvolvimento da Educação (PDE) como uma estratégia do Governo Federal para induzir a ampliação da jornada escolar e a organização curricular, na perspectiva da Educação Integral (BRASIL, 2014).

O programa como um todo é organizado em sete macrocampos: acompanhamento pedagógico; comunicação, uso de mídias e cultura digital e tecnológica; cultura, artes e educação patrimonial; educação ambiental, desenvolvimento sustentável e economia solidária e criativa e educação econômica (educação financeira e fiscal); esporte e lazer; educação em direitos humanos; e promoção da saúde. O macrocampo "acompanhamento pedagógico" é obrigatório para toda escola que se inscreve no programa, os outros seis são opcionais.

As rádios escolares são contempladas no macrocampo “Comunicação, uso de mídias e cultura digital e tecnológica”, que prioriza ações que tratem de Educação em Direitos Humanos, Promoção da Saúde e temas relacionados à Ética e Cidadania (BRASIL, 2014, p. 6). Os documentos de referência do PME incentivam o uso de abordagens inter e transdisciplinares que devem ser "[...] trabalhadas, preferencialmente, de forma e considerando o contexto social dos sujeitos [...]" fomentando "[...] práticas educativas que promovam aos estudantes a compreensão do mundo em que vivem, de si mesmos, do outro, do meio ambiente, da vida em sociedade, das artes, das diversas culturas, das tecnologias e de outras temáticas" (BRASIL, 2014, p. 8). A produção de rádio na escola deve então ser pensada para facilitar o acesso e a difusão de informação sobre direitos e liberdades fundamentais, estimulando práticas de respeito às diferenças, assim como campanhas nas quais os estudantes se engajem na promoção dos direitos humanos e da saúde na escola e na comunidade, além da prevenção de doenças e agravos.

Um exame sistemático no conjunto de documentos que compõem o PME e, em especial, os que dialogam com o macrocampo "Comunicação, uso de mídias e cultura digital e tecnológica", sugere que os referenciais de maneira geral enfatizam a importância de tratar da linguagem midiática e da produção de conteúdo na escola. Os outros conceitos-chave da mídia-educação descritos anteriormente (audiência, representação e instituições de mídia) parecem menos importantes para o PME, como mostra a Tabela 1. 
A análise contemplou quatorze documentos disponíveis no site do MEC entre manuais, resoluções, textos de referência e materiais didáticos de aplicação. Foram analisados também dois mapeamentos das experiências já realizadas no Brasil, que demonstram o alcance do macrocampo e o interesse das escolas em aderir à rádio escolar. Foi dada atenção especial ao "Manual Operacional” do PME, aos "Cadernos do Cenpec" e à brochura "Escola que Protege", que condensam a parte mais significativa de orientações relativas a abordagens e práticas pedagógicas sobre o uso de mídias.

Tabela 1: Resultado da análise de conteúdo de documentos do Programa Mais Educação com foco no uso de mídias

\begin{tabular}{lllllll}
\hline \multirow{2}{*}{ DOCUMENTOS } & \multicolumn{2}{c}{ CATEGORIAS $^{\mathbf{3}}$} & \multicolumn{2}{c}{ Total por documento } \\
\cline { 2 - 6 } & Representação & Audiência & Produção & Linguagem & \\
\hline 1. & Manual Operacional & 1 & 1 & 6 & 5 & 13 \\
\hline 2. Cadernos Cenpec & 2 & 3 & 5 & 8 & 18 \\
\hline 3. $\quad$ Escola que Protege & 3 & 2 & 3 & 1 & 9 \\
\hline Total de categoria & 6 & 6 & 14 & 14 & \\
\hline \multicolumn{5}{c}{ Fonte: Elaborado pelas autoras }
\end{tabular}

Para além da quantificação das informações, o estudo das três publicações trouxe à tona algumas tendências e particularidades, sintetizadas a seguir.

O Manual Operacional, que reúne as ementas dos macrocampos, contempla, de algum modo, a educação para a mídia na ementa do macrocampo "Comunicação, Uso de Mídias e Cultura Digital” (BRASIL, 2014, p. 9), quando discorre sobre o potencial das atividades com as rádios escolares: elas oferecem às escolas a "[...] possibilidade de criarem e fortalecerem ecossistemas comunicativos, estimulando práticas de socialização e convivência no espaço escolar. O Manual também contempla o conceito de multimodalidade quando dá orientações sobre como abordar o tema Direitos Humanos: "Por meio de múltiplas linguagens artísticas, entre as quais a fotografia, o vídeo, a literatura, a música e a dança, é possível abordar o tema Direitos Humanos de maneira transversal e interdisciplinar [...]” (BRASIL, 2014, p. 9).

\footnotetext{
${ }^{3}$ Como não foram encontrados registros referentes ao conceito-chave "instituições de mídia" na análise exploratória de toda a amostra, este conceito-chave não tem registro na tabela.
} 
O macrocampo "Cultura, Artes e Educação Patrimonial” sugere a criação de cineclubes na escola, mencionando discussão sobre processos de distribuição, produção e recepção de mídias, "flertando" assim com os conceitos-chave de audiências e instituições. O conceitochave da representação está implícito nas recomendações para o uso da fotografia “"[...] como dispositivo pedagógico de reconhecimento das diferentes imagens e identidades que envolvem a realidade dos estudantes, da escola e da comunidade" (BRASIL, 2014, p. 11).

Enfim, parece que o Manual Operacional tenta integrar uso de mídias e promoção de conhecimento sobre Direitos Humanos por meio da participação ativa dos sujeitos na comunicação. Há orientação explícita para o uso de metodologias e práticas pedagógicas progressistas, para a participação coletiva e para o ensino e a aprendizagem fora do espaço e tempo formais da escola, mas não há referências explícitas ao estudo das mídias em si.

O PME inclui em seus documentos publicações do Centro de Estudos e Pesquisas em Educação, Cultura e Ação Comunitária (CENPEC) que discorrem sobre educação informal, contemplando o uso de tecnologias nesses espaços de aprendizagem. Foram identificadas menções ao estudo do comportamento da audiência, por exemplo, em atividades de recepção de filmes vistos como oportunidade para "[...] reeducar o olhar do público, viciado nos códigos estabelecidos pelo cinema do espetáculo" (CENPEC, 2006, p. 161).

O caderno "Escola que Protege" fornece um panorama histórico sobre violência contra crianças e adolescentes, tratando, inclusive, da violência simbólica que se perfaz na "[...] difusão de uma superioridade fundada em mitos, símbolos, imagens, mídia e construções sociais que discriminam, humilham, excluem”. A escola, como instituição formadora, "[...] tem um papel fundamental na desconstrução da violência simbólica e da cultura da inferiorização de gênero, de raça, de classe social e de geração" (BRASIL, 2008, p. 33). O documento conclui que "[...] torna-se indispensável que os educadores (pais e professores) estejam preparados para enfrentar essa questão discutindo-a com os jovens sob sua responsabilidade e orientandoos sobre como se proteger dessas ações criminosas" (BRASIL, 2008, p. 45), mas não sugere meios para que a preparação aconteça.

O estudo dos documentos indica, portanto, que há espaço para incluir referências internacionais de mídia-educação nas atividades das rádios escolares.

\subsection{Desenho das oficinas}


O diálogo entre as demandas da Rádio Escola do PME e os referenciais internacionais de mídia-educação foi materializado em um programa de 40 horas de atividades, com 10 blocos de 4 horas cada, sendo cinco destes presenciais e os demais a distância, utilizando a plataforma Moodle institucional da universidade. O público-alvo foi formado por estudantes e professores de Ensino Médio de uma escola pública de Minas Gerais que já tinha a rádio escola, obtida com recursos do Programa Mais Educação.

O plano de trabalho contemplou cinco etapas, sintetizadas no Quadro 1.

Quadro 1: Etapas das oficinas de rádio

\begin{tabular}{|c|c|c|c|}
\hline $\begin{array}{l}\text { ETAPA/ } \\
\text { DESCRIÇÃO }\end{array}$ & CONTEÚDOS & ATIVIDADES & $\begin{array}{c}\text { CARGA } \\
\text { HORÁRIA }\end{array}$ \\
\hline $1 \begin{array}{l}\text { Cultura } \\
\text { radiofônica }\end{array}$ & $\begin{array}{l}\text { História e evolução do } \\
\text { rádio, curiosidades sobre } \\
\text { essa mídia }\end{array}$ & $\begin{array}{l}\text { Ouvir programas antigos famosos como o } \\
\text { Repórter Esso, conhecer a história da exibição } \\
\text { de "Guerra dos Mundos" de Orson Welles e } \\
\text { sua repercussão à época, discutir o significado } \\
\text { cultural do rádio para os jovens de antigamen- } \\
\text { te a partir da música "Rock'n'roll” do Velvet } \\
\text { Underground. Explorar sites, aplicativos web e } \\
\text { software que ajudam a produzir conteúdo } \\
\text { radiofônico }\end{array}$ & 4 horas \\
\hline $2 \begin{array}{l}\text { Linguagem } \\
\text { radiofônica }\end{array}$ & $\begin{array}{l}\text { Gêneros e formatos, } \\
\text { elementos da linguagem: } \\
\text { paisagens sonoras, locu- } \\
\text { ção, sonoras, BG, efeitos } \\
\text { sonoros, vinhetas }\end{array}$ & $\begin{array}{l}\text { Usando um guia impresso, ouvir diversos } \\
\text { tipos de programas e identificar o gênero (fic- } \\
\text { ção, não-ficção ou híbrido), o formato predo- } \\
\text { minante (jornal, entrevista, esquete humorísti- } \\
\text { ca, publicidade etc). } \\
\text { Ouvindo um programa de rádio sobre como } \\
\text { fazer uma reportagem em rádio, explorar os } \\
\text { principais elementos da linguagem radiofônica } \\
\text { (locução, sonoras, vinheta, BG etc). } \\
\text { "Decupar" a música "Rapsody in Blue" dos } \\
\text { irmãos Gershwin, para explorar as emoções e } \\
\text { imaginações que a sonoridade pode aflorar no } \\
\text { ouvinte. }\end{array}$ & 4 horas \\
\hline 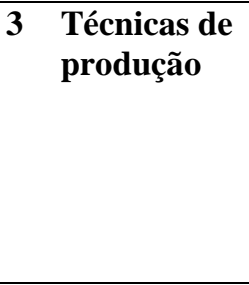 & $\begin{array}{l}\text { Script, técnicas de entre- } \\
\text { vista, técnicas de edição } \\
\text { com o Audacity }\end{array}$ & $\begin{array}{l}\text { Usando informações do material impresso, } \\
\text { elaborar um programa de não-ficção que use } \\
\text { música, locução e sonoras para discutir um } \\
\text { problema da escola. Criar estrutura narrativa, } \\
\text { redigir o script, gravar entrevistas, selecionar } \\
\text { música que dialogue com a temática e editar o } \\
\text { programa usando o software Audacity. }\end{array}$ & 24 horas \\
\hline $4 \begin{array}{l}\text { Resposta da } \\
\text { audiência }\end{array}$ & $\begin{array}{l}\text { Pesquisa informal de } \\
\text { recepção }\end{array}$ & $\begin{array}{l}\text { Usando sites de compartilhamento de conteú- } \\
\text { do como o SoundCloud e um blog, publicar } \\
\text { todos os programas produzidos, seguidos de } \\
\text { um formulário de avaliação para ser respondi- } \\
\text { do por colegas, professores, familiares. Reunir } \\
\text { essas respostas e avaliar como a audiência } \\
\text { respondeu aos programas elaborados. }\end{array}$ & 4 horas \\
\hline
\end{tabular}




\begin{tabular}{|l|l|l|l|}
\hline 5 Análise & Projeto inicial e resulta- \\
crítica & $\begin{array}{l}\text { Organização de um seminário onde cada gru- } \\
\text { dos concretos obtidos nas } \\
\text { produções dos alunos apresentar os dados coletados no formu- } \\
\end{array}$ & $\begin{array}{l}\text { lário e fará uma autoavaliação comparando a } \\
\text { ideia inicial, a produção que de fato realiza- } \\
\text { ram e o modo como a audiência interpretou a } \\
\end{array}$ & $\begin{array}{l}\text { mensagem. } \\
\end{array}$
\end{tabular}

Fonte: Elaborado pelas autoras

As cinco etapas foram desenhadas para tratar, de maneira sistêmica, dos quatro conceitos-chave da mídia-educação, com atividades que transitassem por diversas linguagens, fomentando o exercício de multiletramentos. Leitura de mensagens (como a análise da música “Rock'n'roll” e a discussão sobre o Repórter Esso), características da linguagem radiofônica e técnicas de produção, compartilhamento na rede e observação das respostas da audiência com posterior autoavaliação compuseram a sequência didática para as oficinas. Os materiais didáticos, os exemplos, as templates e as produções dos participantes foram postados na sala virtual, bem como compartilhados nas páginas pessoais de redes sociais. Cada participante foi incentivado a criar uma conta pessoal no SoundCloud, conhecendo assim um espaço de compartilhamento para além do Facebook.

O diálogo com as demandas do macrocampo foi estabelecido na temática proposta para as produções, que deveriam discutir problemas e desafios das comunidades de origem dos participantes. Para tanto, as atividades de produção foram guiadas por um material didático organizado em quatro tópicos: o primeiro apresenta a ideia de "soluções próprias da comunidade" ${ }^{4}$ e as metodologias que podem ser usadas para pensar nessas soluções; o segundo tópico desenvolve habilidades para contar histórias como ferramenta de diagnóstico e investigação de problemas e desafios; o terceiro tópico ensina a transformar o problema e a solução imaginada em uma história atraente para ser compartilhada na internet. O último tópico desenvolve técnicas para usar a linguagem radiofônica na produção de narrativas. Juntas, as cinco etapas e os quatro tópicos oferecem conhecimento relevante para que professores e alunos possam discutir e se engajar em questões relacionadas ao seu ambiente próximo e, nesse processo, desenvolvem habilidades de leitura crítica da mídia.

\footnotetext{
${ }^{4}$ Soluções próprias da comunidade são práticas desenvolvidas e executadas por comunidades das mais diversas, por elas mesmas e para elas mesmas, desde que observadas algumas características: trata-se de algo que a comunidade precisa, tem controle sobre a prática, oferece uma solução justa e que traz benefícios, é boa para o meio ambiente e é autossuficiente (BERARDI EL AL, 2014).
} 


\section{RESULTADOS E DISCUSSÃO}

Ao término das oficinas, foram produzidos cinco programas:

"Até quando você vai ficar parado" tem quatro minutos e vinte e sete segundos de duração e conta a história de Ana, uma garota que muda de cidade, deixa a escola que ela tanto gostava e vai estudar em uma escola bagunçada e feia. A história de Ana motiva uma mensagem de mobilização: vamos preservar o que temos e nos organizarmos para melhorar o que é preciso. O programa termina com a música “Até quando você vai ficar parado?” de Gabriel o Pensador, que dialoga com a crítica à apatia dos estudantes.

“A história da música" tem quatro minutos e oito segundos e faz uma cronologia do desenvolvimento da música. À medida em que a narrativa avança, há melodias que exemplificam o que foi dito. A locução segue um tom professoral e não são citadas as fontes de referência.

“Joga fora no lixo" tem um minuto e cinquenta e cinco segundos de duração e simula o diálogo entre um homem e uma mulher. Ele fala ao celular distraidamente e joga lixo na rua e, por isso, recebe uma repreensão. Esse diálogo motiva uma pequena discussão sobre comportamentos inadequados no manejo do lixo e que dificultam a vida nas grandes cidades. A locução é ilustrada com a música "Joga fora no lixo", da cantora Sandra de Sá.

“Água, um bem indispensável” tem dois minutos e quarenta e três segundos. Mescla narração e trechos da música "Planeta água", de Guilherme Arantes. O narrador fala sobre a importância da água e chama a atenção para o uso racional.

Finalmente, "Bullying" tem um minuto e quarenta e seis segundos e explica essa prática também de forma professoral. A narração é mesclada com efeitos sonoros que tornam o programa mais atraente. Ao final, a narradora pede para que o público pare de praticar bullying na escola.

Como já destacado anteriormente, avaliação dos resultados foi feita a partir de três instrumentos: o material produzido pelos participantes, as anotações no diário de campo e um questionário de avaliação do curso. Os dados foram então avaliados segundo três categorias: engajamento dos participantes na proposta, qualidade das produções e percepção dos participantes no que se refere à relevância e viabilidade da proposta. 


\subsection{Qualidade das produções}

De um modo geral, os programas produzidos empregam com competência os elementos da linguagem radiofônica estudados, discutem questões relevantes para a comunidade (exceto o programa sobre a história da música) e são orientados para algum tipo de mobilização. Mas acabam reproduzindo representações hegemônicas, como aquela de que a responsabilidade pela falta de água é unicamente o desperdício individual. Os participantes souberam empregar características do gênero midiático em estudo, usaram o software para editar e remixar o conteúdo, e souberam se dirigir a um público específico.

\subsection{Percepções dos participantes}

O questionário trouxe à tona os aspectos valorizados: aprender a trabalhar coletivamente, aprender a fazer um programa radiofônico, aprender a usar um software de edição de áudio e aprender a interpretar textos e áudios de maneira mais apurada. As críticas registradas se referiam à duração das oficinas, que foram curtas na opinião dos participantes. Uma estudante registrou que as aulas de mídia-educação ajudaram-na muito na escola, e que ela gostaria que se fossem estendidas a outras séries, para ajudar o outros alunos.

Parte significativa dos registros do diário de campo se referem às dificuldades enfrentadas para ministrar as oficinas, em geral problemas de infraestrutura: um professor falta e um participante da oficina precisa ir substituí-lo, cabos somem, os computadores não funcionam e não há suporte técnico, a biblioteca precisa ser usada por outra turma, os professores são chamados às pressas para reuniões na Superintendência de Ensino e não podem ir às oficinas, não há como imprimir os scripts, o calor é insuportável e a sala não tem ventilação.

\subsection{Engajamento na proposta}

A despeito de todas as dificuldades, verificou-se significativo engajamento dos participantes na realização de todas as tarefas, desde as mais familiares de discussão em grupo, até as menos comuns como fazer locução e usar software de edição de áudio. Houve assiduidade 
nas oficinas e as tarefas foram realizadas no tempo previsto. Os professores foram mais engajados do que os alunos.

\subsection{Percepções dos participantes?}

A avaliação da relevância da proposta na perspectiva do público escolar foi feita a partir dos registros no diário de campo e das respostas ao questionário. Este é o critério mais difícil de avaliar, porque a impressão dos participantes está diretamente relacionada às condições de infraestrutura da escola. Este problema já é conhecido: não raro, toda vez que um professor da educação básica pública resolve inovar acaba tendo que lidar com tantos problemas, que a inovação em si acaba virando mais um problema. Muitas vezes, é por essa razão que os professores são resistentes: a estrutura administrativa da escola, centralizadora e precária, age contra a inovação. No caso específico desta pesquisa, as atividades foram realizadas numa escola, literalmente, cercada de problemas. Pobreza, degradação ambiental e violência fazem parte do dia a dia. O bairro tem presença significativa de traficantes, há um matadouro que polui o rio que corta o bairro, o serviço público de transporte é ruim e a escola está em péssimas condições.

Apesar de todos os problemas citados, em diversos momentos os professores manifestaram o interesse em dar continuidade à proposta, em receber mais formação para trabalhar com mídias, especialmente no que diz respeito à produção "consciente" de rádio. As vantagens apontadas por eles são o estabelecimento de comunicação mais direta com os alunos, que pode minimizar o problema da falta de motivação dos discentes. Os professores participantes julgaram a proposta "imprescindível no processo educacional”, já que abrange não apenas a fala, mas também escrita, criatividade, responsabilidade.

\section{CONSIDERAÇÕES FINAIS}

O objetivo desta pesquisa, de sugerir aprimoramentos para o uso das rádios escolares integrando-as ao contexto mais amplo da educação para a mídia e da cultura digital parece ter sido atingido com relativo sucesso. O grupo de sujeitos da investigação conseguiu desenvolver a maioria das habilidades de leitura crítica e produção de conteúdo, embora parte signifi- 
cativa das produções não tenha ido além dos lugares-comuns sobre temas controversos largamente disseminados na mídia. Mas isso não é necessariamente um problema. Conforme a fundamentação teórica sobre mídia-educação usada neste estudo, a leitura crítica envolve operações mentais às quais nem professores nem acadêmicos têm acesso direto. É por isso que a parte mais significativa de formação ocorre no processo de produção e na autoavaliação. Comparar a ideia inicial e o resultado final, e localizar esse resultado no espectro de opiniões correntes na mídia sobre aquele tema é o trabalho básico de desenvolvimento de habilidades críticas. Ruim mesmo é a estrutura ofertada pelo governo estadual. 


\section{REFERÊNCIAS}

ASSOCIATION FOR MEDIA LITERACY (AML). Critical Media Literacy Teachable

Moments. Disponível em: <http://www.aml.ca/category/resources/critical-media-literacyteachable-moments/>. Acesso em: 12 mar. 2015.

BARDIN, L. Análise de Conteúdo. São Paulo: Edições 70, 2010.

BERARDI, A. ET AL. Como encontrar e compartilhar soluções próprias da comunidade - Um Manual Prático. Disponível em: <http://projectcobra.org/wpcontent/uploads/PH_PT_Web.pdf>. Acesso em: 22 mar. 2015.

BRASIL. Ministério da Educação. Portaria Normativa Interministerial n. 17. Institui o Programa Mais Educação. Brasília, DF: MEC, 2007.

BRASIL. Ministério da Educação. Decreto-lei n. 7083, de 27 de janeiro de 2010. Dispõe sobre o Programa Mais Educação. Brasília, DF: MEC, 2010.

BRASIL. Ministério da Educação. Secretaria de Educação Continuada, Alfabetização e Diversidade. Escola que Protege: Enfrentando a violência contra crianças e adolescentes. Brasília: MEC, SECAD. 2008, $2^{a}$ edição. Disponível em: 〈http://goo.gl/Hpst9y >. Acesso em: 25 mai. 2013.

BRASIL. Ministério da Educação. Secretaria de Educação Básica. Diretoria de Currículos e Educação Integral. Manual Operacional de Educação Integral. Brasília, 2014. Disponível em: 〈http://goo.gl/SrIjxz >. Acesso em: 10 mai. 2014.

BUCKINGHAM, D. Media Education: literacy, learning and contemporary culture. Londres: Polity Press, 2003.

BURN, A. E DURRAN, J. Media Literacy in Schools: practice, production and progression. Londres: Sage/Paul Chapman Publishing, 2007.

CENPEC, Centro de Estudos e Pesquisas em Educação, Cultura e Ação Comunitária. Cadernos Cenpec n. 2. São Paulo: CENPEC, 2006. Disponível em: 〈http://goo.gl/BILQwg〉. Acesso em: 25 mai. 2013.

COPE, B. e KALANTZIS, M. Multiliteracies: Literacy learning and the design of social Futures. Londres: Routledge: 2000.

COSTA, R. Cultura Digital. 3 ed. São Paulo: Publifolha, 2002.

GIL, A. C. Como elaborar projetos de pesquisa. 4 ed. São Paulo: Atlas, 2002. 
IBGE/NIC.BR. PNAD - Acesso à internet e posse de telefone móvel para uso pessoal. Rio de Janeiro: IBGE, 2007.

JENKINS, H. Cultura da Convergência. São Paulo: Aleph, 2008.

KELLNER, D.; SHARE, J. Educação para a leitura crítica da mídia, democracia radical e reconstrução da educação. Educação \& Sociedade, Campinas, v. 29, n. 104, p. 687-717, out. 2008.

KRESS, G. Multimodality: A social semiotic approach to contemporary communication. Londres: Routledge. 2010.

LUSTED, D. (org.) The Media Studies Book - A Guide for Teachers. Londres: Routledge, 1991.

OFCOM. Ofcom's Strategy and Priorities for the Promotion of Media Literacy - A statement. Londres, 2004. Disponível em 〈www.ofcom.co.uk〉. Acesso 18 março 2015.

QUALIFICATIONS AND CURRICULUM AUTOHORITY. Media Studies - A level performance descriptions. Londres, QCA, 2003.

SIQUEIRA, A. B. Mídia: quer estudar essa matéria? In.: Salto para o Futuro: mídiaeducação e currículo escolar, v. 1, p. 4-18, 2013.

UNESCO. Alfabetização midiática e informacional - Currículo para a formação de professores. Brasília: UNESCO/UFTM, 2013.

WILLIANS, R. Key words. Oxford: Oxford University Press, 1985. 